\title{
Knowledge, beliefs, mental health, substance use, and behaviors related to the COVID-19 pandemic among US adults: a national online survey
}

\author{
Ralph J. DiClemente ${ }^{1}$ (D) Ariadna Capasso ${ }^{1} \cdot$ Shahmir H. Ali ${ }^{1} \cdot$ Abbey M. Jones $^{2} \cdot$ Joshua Foreman $^{1,3} \cdot$ Yesim Tozan $^{4}$
}

Received: 2 December 2020 / Accepted: 14 April 2021 / Published online: 12 May 2021

(C) The Author(s), under exclusive licence to Springer-Verlag GmbH Germany, part of Springer Nature 2021

\begin{abstract}
Aim Given the need for data to inform public health messaging to mitigate the COVID-19 pandemic, this national survey sought to assess the state of COVID-19-related knowledge, beliefs, mental health, substance use changes, and behaviors among a sample of U.S. adults.

Subject and methods In the period March 20-30, 2020, we collected data on COVID-19-related knowledge, awareness and adoption of preventive practices, depression and anxiety (Patient Health Questionnaire-4), stress (Impact of Event Scale-6), pessimism, and tobacco and alcohol use. Differences between age groups (18-39 years, 40-59 years and $\geq 60$ years) were tested using Pearson's chi-squared tests or ANOVAs; associations between drinking and smoking and depression, anxiety, and stress were tested using adjusted logistic regression models.

Results Approximately half of the sample $\left(N_{\text {Total }}=6391\right)$ were 50-69 years old and 58\% were female. COVID-19 knowledge $($ mean $=12.0 ; \mathrm{SD}=1.2)$ and protective practice awareness (mean $=9.1 ; \mathrm{SD}=0.8)$ were high. Among respondents, $44 \%$ had a score consistent with depression and anxiety (PHQ-4 score $\geq 6$ ), and 52\% reported high stress scores ( $\geq$ median of 1.33). COVID19-related anxiety and depression were associated with increased drinking $(\mathrm{AOR}=1.79 ; 95 \% \mathrm{CI}=1.49,2.15)$ and smoking $(\mathrm{AOR}=2.17 ; 95 \% \mathrm{CI}=1.64,2.88)$. High stress scores were also associated with increased drinking $(\mathrm{AOR}=1.80 ; 95 \% \mathrm{CI}=$ $1.49,2.17, p<0.001)$ and smoking $(\mathrm{AOR}=1.75 ; 95 \% \mathrm{CI}=1.31,2.33)$.

Conclusions In spite of high knowledge levels, important gaps were identified. High prevalence of poor mental health outcomes and associated increases in drinking and smoking warrant ongoing risk communications tailoring to effectively disseminate information and expanding psychosocial services, particularly via telehealth, to mitigate the negative mental health impact of COVID-19.
\end{abstract}

Keywords COVID-19 $\cdot$ Novel coronavirus $\cdot$ Risk communications $\cdot$ United States $\cdot$ Alcohol use $\cdot$ Smoking

Ralph J. DiClemente

rjd438@nyu.edu

1 Department of Social and Behavioral Sciences, School of Global Public Health, New York University, 715 Broadway, Suite 1202, New York, NY 10012, USA

2 Department of Epidemiology, School of Global Public Health, New York University, New York, NY, USA

3 Department of Surgery, Ophthalmology, University of Melbourne, Melbourne, Australia

4 Global Health Program, School of Global Public Health, New York University, New York, NY, USA

\section{Background}

The novel coronavirus disease (COVID-19) has rapidly emerged as a pandemic, precipitating the largest global health and economic crisis in recent history (World Health Organization 2020a). Highly transmissible, with relatively high morbidity and mortality rates (Wilson et al. 2020), particularly among older adults (Bai et al. 2020; Chan et al. 2020; Rothe et al. 2020), COVID-19 has already inflicted myriad adverse health, social, and economic consequences, and exacerbated existing health inequities. While many states have enacted social distancing measures to slow viral transmission, there is limited empirical research with regard to people's knowledge, beliefs, and perceptions related to COVID-19 that 
may affect compliance with recommended mitigation measures. Given the disproportionate burden of COVID-19 morbidity and mortality among older adults, age-specific data are also of great importance (Verity et al. 2020). Equally lacking are data on COVID-19-related anxiety, depression, and substance use, which may adversely affect adoption and sustainment of mitigation behaviors (Brooks et al. 2020). Social separation, particularly for prolonged periods, can promote poor mental health outcomes (Lu and Bouey 2020; Person et al. 2004; Shultz et al. 2016). Given the absence of a vaccine, preventing COVID-19's more dire outcomes largely depends on compliance with preventive behaviors, modulated by the public's perceptions of the pandemic (Arons et al. 2020; Fauci et al. 2020; Gandhi et al. 2020; Hartley and Perencevich 2020; Wong et al. 2007b). The development and widespread dissemination of effective risk communication strategies are critical for containment. To optimize the development of effective public health messaging, it is critical to identify gaps in COVID-19-related knowledge, beliefs, and mitigation behaviors.

To address this gap, we implemented an internet-based, nationwide survey of knowledge, beliefs, mental health, and behaviors related to the COVID-19 pandemic among US adults.

\section{Methods}

\section{Participant recruitment}

The sample was a self-selected non-probability sample of social media users aged $\geq 18$ years and residing in the USA who responded to an anonymous web-based survey administered via Qualtrics (Provo, UT, USA) (Ali et al. 2020). To minimize redundant reporting, participants could only complete the survey once (based on IP address). Eligibility was confirmed through two screening questions (age and residence in the USA) at the start of the survey. Survey reporting followed the American Association for Public Opinion Research guidelines (AAPOR 2016). The [redacted] Institutional Review Board reviewed and exempted the study procedures.

Recruitment was facilitated via a social media advertisement campaign through Facebook and its affiliated platforms. Used by $69 \%$ of US adults, Facebook was chosen because it is the most popular social media platform among adults $\geq 65$ years (Perrin and Anderson 2019; Smith and Anderson 2018). A growing body of evidence suggests that Facebook is a valid and effective recruitment tool in health research, resulting in lower costs and shorter recruitment periods than other methods (Whitaker et al. 2017). The advertisements ran for 11 consecutive days, from March 20-30, 2020.

\section{Survey}

The survey questionnaire was developed for this study (see Supplementary File S1 Questionnaire). The survey was informed by the Health Belief Model (HBM), which is a widely used model to explain preventive health behaviors based on knowledge, attitudes, and cues to action (Durham and Casman 2012; Najimi and Golshiri 2013). HBM has previously been utilized to guide surveys for other viral outbreaks, such as H1N1 and Middle East Respiratory Syndrome (MERS) (AlRabiaah et al. 2020; Hasan et al. 2018; Lau et al. 2005; Rubin et al. 2009; Vartti et al. 2009) and for Ebola in the USA (Painter et al. 2017; Painter et al. 2018). The survey was also informed by the World Health Organization (WHO) tool for behavioral insights on COVID-19 (World Health Organization 2020b). The survey included questions on COVID-19 knowledge, risk perceptions, and preventive behaviors, and psychometrically validated mental health scales adapted for this pandemic.

Knowledge of COVID-19 was measured by 13 binary response format (True/False) items, such as "Coronavirus is a contagious disease." Responses consistent with information provided by the CDC as of March 11,2020, were summed to create a composite knowledge score.

Awareness of COVID-19 protective practices was assessed by ten binary response format (True/False) items, that respondents may have considered preventive of COVID-19 infection, such as "Getting a flu shot." Items were selected from previous surveys (Jalloh et al. 2018; Lau et al. 2007; Painter et al. 2017) and updated to reflect behaviors relevant to the current pandemic. Responses consistent with CDC recommendations as of March 11, 2020, were summed to create a composite COVID-19 prevention score.

Adoption of COVID-19 protective practices was assessed by 12 binary response format (Yes/No) items about specific evidence- and non-evidence-based behaviors that respondents may have considered preventive of COVID-19 infection, such as "Started wearing rubber gloves in public."

COVID-19-related changes in tobacco and alcohol use were assessed by the question "Since hearing about the Coronavirus outbreak, has your smoking (tobacco products) and alcohol use behaviors changed?" Response options ranged from "Much more" to "Much less" and included "Not applicable." The variables were re-coded as "more," "less," or "no change."

Anxiety and depression related to COVID-19 were assessed with an adapted version of the four-item Patient Health Questionnaire (PHQ-4) (Jalloh et al. 2018; Lowe et al. 2010). The stem question was, "Over the last 7 days, how often have you been bothered by any of the following problems because of the Coronavirus outbreak?" Response options were rated on a 4-point Likert scale 
ranging from "Not at all" to "Nearly every day." Total scores ranged from 0 to 12 , with higher scores indicative of greater anxiety and depression symptoms. The score was dichotomized based on the clinical cutoff for possible depression and anxiety $(<6$ and $\geq 6$ ). (Lowe et al. 2010) The scale demonstrated internal reliability (alpha $=0.89$ ).

The Impact of Event Scale (IES) and its abbreviated 6item version (IES-6) are widely validated scales to measure subjective stress (Lau et al. 2005; Thoresen et al. 2010; Weiss and Marmar 1997). We adapted the IES-6 scale to measure stress associated with the COVID-19 pandemic. An item example was, "I thought about Coronavirus when I didn't mean to," with four response options ranging from "Not at all" to "Nearly every day." The mean item response was calculated (possible range from 0 to 3), with higher mean scores indicative of more subjective stress. The sample was dichotomized at the median into high and low stress scores. The scale's internal consistency was 0.86 .

Pessimism was assessed by the question: "I am optimistic that the Coronavirus outbreak will be controlled in the next 3 months." Response options on the four-point Likert scale ranged from "Strongly agree" to "Strongly disagree." The variable was reverse coded and dichotomized into a Pessimism variable (Disagree/Strongly Disagree $=0$; Strongly Agree/Agree = 1).

Demographics assessed included sex, race, age category (by decade), employment status, educational attainment, living with children $<18$ years of age, state of residence re-coded by US Census region (U.S. Census Bureau 1984), urban/rural residence, and political party affiliation.

\section{Statistical analysis}

Given the potential importance of age as a demographic risk factor for mortality among people with COVID-19 infection, the sample was categorized into three age groups: (1) 18-39 years, (2) 40-59 years, and (3) $\geq 60$ years. Descriptive statistics characterized respondents' demographics and COVID-19-related knowledge, behaviors, substance use, and mental health for the total sample and the three age categories. Pearson's chisquared tests for categorical variables, and ANOVA tests for continuous variables, were used to examine differences by age categories. Post-hoc pairwise comparisons were also tested. Logistic regression analyses assessed changes in alcohol consumption and smoking associated with anxiety, depression, and stress, controlling for age and race. All analyses were complete case analyses. Statistical analyses were performed using Stata version 15.1 (StataCorp, College Station, TX, USA).

\section{Results}

\section{Sample characteristics}

The sample was comprised of 6391 respondents; 4998 respondents (78\%) completed $100 \%$ of the survey, $1393(22 \%)$ were partial completers (906 completed $<33 \%$ and 487 completed $50 \%-79 \%$ of the items). Respondents took a median of $10.9 \mathrm{~min}$ [interquartile range $(\mathrm{IQR})=9.0,13.4$ ] to complete the full survey.

\section{Sociodemographic characteristics of the sample}

Sociodemographic characteristics of respondents are presented for the entire sample and by age group in Table 1 . Approximately half of the respondents were 50-69 years old and $58 \%$ were female. The majority self-identified as nonHispanic White. Participants were almost uniformly distributed between three of the four major geographic regions in the USA (26-30\% in each), with fewer respondents residing in the West $(15 \%)$. Almost half lived in suburban areas. Approximately, three-fourths of adults under 60 years were employed, compared to a third of those aged 60 years and over.

\section{Knowledge of COVID-19}

Respondents had high COVID-19 knowledge scores [mean = 12.0; standard deviation $(\mathrm{SD})=1.2$; range $=0-13]$ (Table 2) . Most were aware that people infected with Coronavirus could be asymptomatic (89\%), and that a vaccine was unavailable (97\%). One item assessing knowledge of the protective value of alcohol-based hand sanitizers, while high (84\%), was lower relative to other knowledge items. Only $81 \%$ of respondents aged $\geq 60$ years were aware of the protective value of alcoholbased hand sanitizers, lower than respondents aged 40 59 years $(81 \% \geq 60$ vs $86 \% 40-59$ years, $p<0.001)$.

\section{Awareness of COVID-19 protective practices}

Respondents, on average, correctly identified $90 \%$ (mean $=$ 9.1; $\mathrm{SD}=0.8$; range $0-10$ ) of protective practices (Table 2 ). However, some gaps were observed: only $84 \%$ and $51 \%$ of respondents, respectively, were aware that receiving an influenza vaccine did not confer protection against the novel Coronavirus, and that wearing a facemask was protective. Few differences were observed across age groups; with one exception: fewer respondents 60 years and older were aware that the influenza vaccine was not protective against the novel Coronavirus compared to $18-39$ year-olds $(82 \% \geq 60$ years vs $86 \%_{18-39}$ years, $p=0.005$ ). 
Table 1 Characteristics of adult Facebook users in the USA during the COVID-19 outbreak, March 20-30, 2020

\begin{tabular}{|c|c|c|c|c|c|}
\hline & \multirow{2}{*}{$\begin{array}{l}\text { Total } \\
(n=4998)\end{array}$} & \multicolumn{3}{|l|}{ Age group } & \multirow[t]{2}{*}{$P$ value* } \\
\hline & & $\begin{array}{l}-18-39 \\
(n=1231)\end{array}$ & $\begin{array}{l}40-59 \\
(n=2314)\end{array}$ & $\begin{array}{l}60+ \\
(n=1453)\end{array}$ & \\
\hline Female sex, $\%$ *** & 58 & 59 & 56 & 58 & 0.103 \\
\hline Non-Hispanic White race, $\%$ & 92 & 89 & 92 & 96 & $<0.001$ \\
\hline \multicolumn{6}{|l|}{ Geographic region, $\% * * *$} \\
\hline Northeast & 26 & 26 & 26 & 24 & \\
\hline Midwest & 30 & 33 & 29 & 28 & \\
\hline South & 30 & 26 & 30 & 32 & \\
\hline West & 15 & 15 & 15 & 16 & 0.029 \\
\hline \multicolumn{6}{|l|}{ Residence type, \% } \\
\hline Rural & 34 & 28 & 35 & 37 & \\
\hline Suburban & 49 & 51 & 48 & 47 & \\
\hline Urban & 17 & 20 & 16 & 16 & $<0.001$ \\
\hline \multicolumn{6}{|l|}{ Employment status, \% } \\
\hline Employed & 63 & 72 & 77 & 33 & \\
\hline Not employed & 11 & 12 & 13 & 8 & \\
\hline Unpaid labor/student & 7 & 16 & 5 & 2 & \\
\hline Retired & 19 & 0 & 5 & 58 & $<0.001$ \\
\hline \multicolumn{6}{|l|}{ Educational attainment, \% } \\
\hline High school or below & 16 & 16 & 16 & 15 & \\
\hline Some college & 34 & 33 & 35 & 34 & \\
\hline Bachelor's degree & 28 & 30 & 27 & 26 & \\
\hline Master's degree or higher & 23 & 21 & 22 & 25 & 0.138 \\
\hline \multicolumn{6}{|l|}{ Political affiliation, $\%$} \\
\hline Democrat & 34 & 39 & 30 & 35 & \\
\hline Republican & 26 & 19 & 27 & 29 & \\
\hline Other & 19 & 22 & 19 & 15 & \\
\hline Prefer not to disclose & 22 & 20 & 23 & 21 & $<0.001$ \\
\hline
\end{tabular}

Notes: * Pearson's chi-squared test, $* * n=6391, * * * n=4997$

\section{Adoption of COVID-19 protective practices}

Most respondents reported avoiding crowded places and using alcohol-based hand-sanitizers (Table 3). Only 19\% of respondents reported purchasing facemasks. Overall, significant differences were observed across age groups; although the magnitude of differences was relatively modest. Differences across age groups were more pronounced with regard to non-evidence-based protective practices (e.g., taking hot baths and dietary supplements) than to evidence-based practices.

\section{COVID-19-related changes in tobacco and alcohol use}

Among self-identified smokers ( $n=1359$ ), about half indicated no change in their smoking behavior as a result of COVID-19, while $22 \%$ reported smoking more (Table 3 ). With respect to alcohol consumption, 53\% reported no change in drinking behavior, while $25 \%$ reported drinking more. There was an observed age gradient in those reporting increased drinking: $34 \%$ of respondents aged 18-39 years reported increased drinking compared to $25 \%$ of those aged $40-59$ years and $15 \%$ of those aged 60 years or more (all differences $p<0.001$ ).

\section{Mental health indicators: anxiety, depression, stress, and pessimism}

COVID-19-related anxiety and depression symptoms experienced within the week prior to survey participation were high; $44 \%$ of respondents had a score consistent with depression and anxiety (PHQ-4 score of $\geq 6$ ) (Table 4). Notably, $85 \%$ of respondents reported "feeling nervous, anxious, or on edge." Stress levels were also high, with 52\% reporting high scores (at or above the median of 1.33). Similarly, $47 \%$ of respondents reported "pessimism" about the COVID-19 pandemic being resolved in the next 3 months. Differences were observed between age groups for both anxiety/depression and 
Table 2 Accurate knowledge of COVID-19 facts and protective practices among 5960 Facebook users in the USA, March 20-30, 2020

\begin{tabular}{llll}
$\begin{array}{l}\% \text { correct, } \\
\text { total } \begin{array}{l}\% \text { correct } \\
\text { sample }\end{array}\end{array}$ & $\begin{array}{l}P \text { value* } \\
\text { by age group }\end{array}$ & \\
\cline { 2 - 4 }$(n=5960)$ & $(n=1512)$ & $\begin{array}{l}40-59 \\
(n=2744)\end{array}$ & $\begin{array}{l}60+ \\
(n=1704)\end{array}$ \\
\hline
\end{tabular}

COVID-19 knowledge

Coronavirus is a contagious disease (T), \% 99

A person infected with Coronavirus is not contagious until after symptoms appear (F), \% 96

Coronavirus cannot be spread through sneezing and coughing (F), \% 93

Currently, there is an FDA approved drug for treating individuals with Coronavirus (F), \% 90

Coronavirus can live on surfaces outside of the body for a few hours or several days (T), \% 98

There is no vaccine currently available to prevent infection with Coronavirus (T), \% 97

$\begin{array}{ll}\text { Children are at high risk for complications from Coronavirus (F), \% } & 79\end{array}$

Older people with other health conditions are more likely to die from Coronavirus (T), \% 98

People with Coronavirus can have no symptoms at all (T), \%

Most people with Coronavirus will have severe or critical symptoms (F), \%

Alcohol-based hand sanitizers cannot protect you from Coronavirus $(\mathrm{F}), \%$

Coronavirus may be transmitted by mosquito bites $(\mathrm{F}), \%$

Coronavirus originated from animals $(\mathrm{T}), \%$

COVID-19 knowledge score (range 0-13), mean (SD)

COVID-19 protective practices awareness

Washing your hands frequently with soap and water (T), \%

Getting a flu shot (F), \%

Wearing a face mask (T), \%

Stop going to school/work (T), \%

Wiping potentially contaminated surfaces with a disinfectant $(\mathrm{T}), \%$

Staying away from Asian people (F), \%

Staying away from people who sneeze and cough (T), \%

Avoiding touching your eyes, nose and mouth (T), \%

Taking antibiotics (F), \%

Stop eating Chinese food (F), \%

COVID-19 protective practices awareness score (range $0-10$ ), mean (SD)

\begin{tabular}{lllll}
9 & 99 & 99 & 99 & 0.655 \\
6 & 96 & 96 & 96 & 0.855 \\
3 & 91 & 93 & 93 & 0.151 \\
0 & 90 & 90 & 91 & 0.433 \\
8 & 99 & 98 & 98 & 0.085 \\
7 & 97 & 97 & 97 & 0.761 \\
9 & 81 & 80 & 77 & 0.003 \\
8 & 99 & 98 & 98 & 0.075 \\
9 & 91 & 90 & 88 & 0.020 \\
9 & 89 & 89 & 88 & 0.665 \\
4 & 84 & 86 & 81 & $<0.001$ \\
5 & 95 & 95 & 96 & 0.360 \\
0 & 92 & 91 & 88 & $<0.001$ \\
$2.0(1.2)$ & $12.0(1.2)$ & $12.0(1.2)$ & $11.9(1.2)$ & $<0.001$ \\
& \multicolumn{5}{c}{ correct, } & $\%$ correct & & & \\
by age group & & $P$ value* \\
ample & $18-39$ & $40-59$ & $60+$ & \\
9 & 99 & 100 & 99 & 0.099 \\
4 & 86 & 83 & 82 & 0.014 \\
1 & 50 & 52 & 51 & 0.383 \\
4 & 94 & 93 & 94 & 0.373 \\
9 & 99 & 99 & 99 & 0.532 \\
6 & 95 & 96 & 96 & 0.414 \\
9 & 97 & 97 & 97 & 0.537 \\
9 & 99 & 99 & 99 & 0.264 \\
9 & 95 & 96 & 97 & 0.056 \\
$(0.8)$ & $9.1(0.8)$ & $9.1(0.8)$ & $9.1(0.8)$ & 0.638
\end{tabular}

Notes: SD standard deviation, * Pearson's chi-squared test for categorical variables and ANOVA for continuous variables

stress: older age was associated with lower proportion of identified symptoms of anxiety, depression, and stress. Among 18-39-year-olds, 57\% had PHQ-4 scores $\geq 6$ compared to $33 \%$ of $\geq 60$ year-olds $(p<0.001)$. Respondents aged 18 39 years were more likely to report high stress scores than adults aged $\geq 60\left(67 \%_{18-39 \text {-year-olds }}\right.$ versus $39 \% \geq 60$ years, $p<0.001)$.

\section{Associations between mental health, stress, and substance use}

Adjusted analyses, controlling for age and race, showed that respondents reporting symptoms of anxiety and depression (PHQ-4 score $\geq 6$ ) were $79 \%$ more likely than those below the clinical cutoff to report drinking more [adjusted odds ratio $(\mathrm{AOR})=1.79 ; 95 \%$ confidence interval $(\mathrm{CI})=1.49,2.15, p<0.001]$ and more than twice as likely to report smoking more $(\mathrm{AOR}=2.17 ; 95 \% \mathrm{CI}=$ $1.64,2.88, p<0.001)$ in response to the COVID-19 pandemic (Table 5). A similar pattern was observed with stress symptoms, whereby respondents with high stress levels were $80 \%$ more likely to report increased drinking $(\mathrm{AOR}=1.80 ; 95 \% \mathrm{CI}=1.49,2.17, p<0.001)$, and $75 \%$ more likely to report increased smoking $(\mathrm{AOR}=1.75$; $95 \% \mathrm{CI}=1.31,2.33, p<0.001)$ relative to those with low stress levels. 
Table 3 Adoption of COVID-19 protective practices among a sample of US adult Facebook users $(n=5486)$, March 20-30, 2020

\begin{tabular}{|c|c|c|c|c|c|}
\hline & \multirow{4}{*}{$\begin{array}{l}\text { Total } \\
\text { sample } \\
(n= \\
5486) \\
\% \text { endor }\end{array}$} & \multicolumn{3}{|c|}{ Age groups } & \multirow{4}{*}{$\begin{array}{l}P \\
\text { value* }\end{array}$} \\
\hline & & \multirow{3}{*}{$\begin{array}{l}18-39 \\
(n= \\
1364) \\
\text { ing each }\end{array}$} & \multirow{3}{*}{$\begin{array}{l}40-59 \\
(n= \\
2541)\end{array}$} & \multirow{3}{*}{$\begin{array}{l}60+ \\
(n= \\
1581)\end{array}$} & \\
\hline & & & & & \\
\hline & & & & & \\
\hline \multicolumn{6}{|l|}{ To protect myself from COVID-19, I... } \\
\hline $\begin{array}{l}\text { Got a flu shot (or had my children get a flu shot) after } \\
\text { hearing about Coronavirus, \% }\end{array}$ & 8 & 7 & 8 & 10 & 0.025 \\
\hline Purchased a face mask, $\%$ & 19 & 17 & 20 & 20 & 0.065 \\
\hline Started working from home, $\%$ & 63 & 64 & 63 & 64 & 0.738 \\
\hline $\begin{array}{l}\text { Started using hand-sanitizer and/or washing my hands } \\
\text { more often, } \%\end{array}$ & 96 & 97 & 96 & 97 & 0.532 \\
\hline Started drinking more fluids and/or getting more rest, $\%$ & 77 & 74 & 75 & 81 & $<0.001$ \\
\hline Started taking antiviral and/or antibiotics, $\%$ & 2 & 4 & 2 & 2 & 0.001 \\
\hline $\begin{array}{l}\text { Started taking dietary supplements (e.g., vitamins, } \\
\text { probiotics), \% }\end{array}$ & 37 & 39 & 37 & 34 & 0.008 \\
\hline Avoided using public transportation, $\%$ & 88 & 90 & 86 & 88 & 0.001 \\
\hline Kept away from crowded places, $\%$ & 97 & 97 & 97 & 98 & 0.099 \\
\hline $\begin{array}{l}\text { Started cleaning and/or disinfecting things that I might } \\
\text { touch (e.g., doorknobs, phone), } \%\end{array}$ & 90 & 89 & 91 & 89 & 0.081 \\
\hline Started wearing rubber gloves in public, $\%$ & 25 & 22 & 25 & 29 & $<0.001$ \\
\hline Started taking more hot baths, $\%$ & 11 & 15 & 11 & 9 & $<0.001$ \\
\hline \multicolumn{6}{|l|}{ COVID-19-related changes in tobacco and alcohol use } \\
\hline \multicolumn{6}{|l|}{ Smoking (tobacco products) ${ }^{\mathrm{a}}$} \\
\hline Smoking less & 26 & 31 & 23 & 27 & \\
\hline Did not change & 51 & 45 & 55 & 49 & \\
\hline Smoking more & 22 & 24 & 21 & 23 & 0.015 \\
\hline \multicolumn{6}{|l|}{ Drinking (alcohol) ${ }^{\mathrm{b}}$} \\
\hline Drinking less & 22 & 26 & 21 & 20 & \\
\hline Did not change & 53 & 40 & 54 & 64 & \\
\hline Drinking more & 25 & 34 & 25 & 15 & $<0.001$ \\
\hline
\end{tabular}

\section{Discussion}

Overall, respondents had high levels of COVID-19 knowledge and awareness of protective practices. Most were aware that a vaccine was unavailable and to avoid congregating in crowded places, a key COVID-19 mitigation strategy (Ferguson et al. 2020; IHME 2020). However, purchase of facemasks was low. This may be attributable to mixed public health messaging at the time of the survey (March 2020) about the effectiveness of facemasks as a personal protective practice, and the limited availability of masks to the public (Keshtkar-Jahromi et al. 2020). Another gap was the relatively low awareness about alcohol-based hand sanitizers as a protective practice. These findings suggest that while adults are largely cognizant of accurate information about COVID-19 and preventive practices, some gaps remain to be addressed.
As our scientific understanding of COVID-19 improves continuously with respect to transmission, treatment, and prevention, public attitudes towards COVID-19 will also likely evolve. Public health messaging will need to rapidly respond and adapt to both. Furthermore, COVID-19 is likely to require sustained public health action in the foreseeable future. Research on recent global emerging disease outbreaks, such as SARS and H1N1, has shown that public perceptions and behaviors can change significantly during the course of outbreaks, and several studies have highlighted the importance of understanding the public's response (Lau et al. 2011; Lau et al. 2003; Leung et al. 2005; Wong et al. 2007b). Therefore, monitoring perceptions and behaviors over time in response to changes in the COVID-19 pandemic, and its containment strategies, is warranted, and can provide policymakers with useful information to ensure continued 
Table 4 Mental health related to the COVID-19 outbreak among a sample of U.S. adults $(n=5044)$, March 20-30, 2020

\begin{tabular}{|c|c|c|c|c|c|}
\hline & \multirow{4}{*}{$\begin{array}{l}\text { Total } \\
\text { sample }\end{array}$} & \multicolumn{3}{|c|}{ Age groups } & \multirow{4}{*}{$\begin{array}{l}P \\
\text { value* }\end{array}$} \\
\hline & & \multirow{3}{*}{$\begin{array}{l}18-39 \\
(n= \\
1242) \\
\text { g each }\end{array}$} & \multirow{3}{*}{$\begin{array}{l}40-59 \\
(n= \\
2336) \\
\text { ptom or }\end{array}$} & \multirow{3}{*}{$\begin{array}{l}60+ \\
(n= \\
1466) \\
\text { an (SD) }\end{array}$} & \\
\hline & & & & & \\
\hline & & & & & \\
\hline \multicolumn{6}{|c|}{ PHQ-4 scale (anxiety and depression symptoms in past 7 days) } \\
\hline Feeling nervous, anxious, or on edge?, \% & 85 & 92 & 86 & 77 & $<0.001$ \\
\hline Not being able to stop or control worrying?, $\%$ & 69 & 82 & 70 & 57 & $<0.001$ \\
\hline Feeling down, depressed, or hopeless?, \% & 64 & 75 & 65 & 53 & $<0.001$ \\
\hline $\begin{array}{l}\text { Little interest or pleasure in doing things (that I used to } \\
\text { enjoy)?, \% }\end{array}$ & 56 & 63 & 57 & 48 & $<0.001$ \\
\hline PHQ- 4 score of $=>6$ is the cutoff ${ }^{a}$ & 44 & 57 & 45 & 33 & $<0.001$ \\
\hline IES-6 (\% respondents with median+scores) & 52 & 67 & 52 & 39 & $<0.001$ \\
\hline Pessimism about COVID-19 & 47 & 49 & 46 & 45 & 0.079 \\
\hline
\end{tabular}

Notes: $S D=$ standard deviation, PHQ-4 = The Patient Health Questionnaire-4, ES-6 = Impact of Event Scale-6, * Pearson's chi-squared tests for categorical variables and ANOVA for continuous variables

${ }^{\text {a }}$ Scores $\geq 6$ on the PHQ-4 may be indicative of anxiety and depression

${ }^{\mathrm{b}}$ Mean IES-6 score

${ }^{\mathrm{c}}$ Responded disagree or strongly disagree to "... being optimistic about COVID-19 being under control within 3 month"

${ }^{\mathrm{d}}$ Denominator $n=5167$ compliance with key recommended mitigation behaviors (Brug et al. 2009).

Of particular concern is the high prevalence of COVID-19related depression, anxiety, stress, and pessimism, and increases in alcohol and tobacco use. While the impact of the COVID-19 pandemic has been predominantly measured in terms of morbidity and mortality (Dong et al. 2020), the myriad adverse societal consequences may be precipitating a "hidden epidemic" of mental illness that is not receiving adequate attention (Brooks et al. 2020). Indeed, the American Psychological Association has predicted the need for a scaled-up response to traumatic stress resulting from the pandemic (Chang et al. 2013; Horesh and Brown 2020). Outbreaks such as H1N1 negatively impacted the mental health not only of survivors (Mak et al. 2009) and healthcare workers (Chen et al. 2006), but also of communities (Elizarrarás-Rivas et al. 2010; Wheaton et al. 2012; Wong et al. 2007a). Furthermore, suicide rates increased by up to 6.4\% following the 2008 financial crisis (Chang et al. 2013). Given that the COVID-19 pandemic is driving a global economic recession, similar trends may emerge.

Depression and anxiety already constitute the leading cause of disability worldwide (Friedrich 2017). Exacerbation of their burden in the USA may produce unforeseen public health and economic consequences long after the COVID-19 pandemic is controlled. Therefore, policymakers should allocate resources for psychosocial support to alleviate both the personal and societal burden of a mental health crisis. The
Table 5 Substance use associated with depression, anxiety and stress during the COVID-19 outbreak

\begin{tabular}{lll}
\hline & $\begin{array}{l}\text { Adjusted odds ratio } \\
(95 \% \text { confidence interval)* }\end{array}$ & $P$ value \\
\hline PHQ-4 score at or above depression and anxiety cutoff & & $<0.001$ \\
Drinking more (compared to drinking same/less) & $1.79(1.49,2.15)$ & $<0.001$ \\
Smoking more (compared to smoking same/less) & $2.17(1.64,2.88)$ & $<0.001$ \\
Scores at median or above on the Impact of Event Scale-6 & & $<0.001$ \\
Drinking more (compared to drinking same/less) & $1.80(1.49,2.17)$ & $1.75(1.31,2.33)$ \\
Smoking more (compared to smoking same/less) & $1.75(1.3)$ & \\
\hline
\end{tabular}

Notes: PHQ-4 = The Patient Health Questionnaire-4, * Logistic regressions adjusted for age and race. The PHQ-4 score was evaluated above the clinical cutoff score for depression and anxiety (PHQ-4 score $\geq 6$ ); IES-6 was evaluated as high and low values based on a median split (median $=1.33)$ 
observed associations between stress, substance use, and depression and anxiety suggest that these factors may be interrelated adverse consequences of the COVID-19 pandemic. Although there is limited research on substance use following viral outbreaks, increases in problem alcohol use were observed among hospital employees in China during the 2003 SARS outbreak (Wu et al. 2008). Thus, confronting these challenges may necessitate enhancing access to substance use treatment and mental health services. Given the scope and disruptive effect of COVID-19 relative to other outbreaks (Shultz et al. 2015), mental health and substance-use interventions utilized after natural disasters (Jaycox et al. 2010; Waelde et al. 2008) can provide valuable guidance. Resiliency from the short term mental, social, and economic impacts of COVID-19 will require intense study (Abramson 2020).

Even though many states have instated social distancing measures, which may preclude face-to-face counseling with healthcare providers, opportunities remain to utilize online and telehealth counseling services. These services are compliant with social distancing policies, and can play a critical role in coping with the adverse consequences of COVID-19, such as loneliness, income loss, and pessimism. One technological strategy to enhance self-care may include the use of smartphone applications to monitor and link users to services (Bakker et al. 2016, 2018). Distance telehealth counseling strategies are not only valuable, but may be essential to confront the mental health and substance-use threats posed by the COVID-19 pandemic.

During a pandemic, accurate and verifiable information is essential to dispel misconceptions and mitigate fears and ambiguity that could result in the adoption of non-evidencebased practices, maladaptive coping strategies, or use of unproven therapeutics. Non-evidence-based treatments are not solely ineffectual; they are dangerous. Complex medical information, such as COVID-19 virology, immunology, medical treatments, and epidemiology, needs to be clear, consistent, and understandable. Thus, there is a need to improve risk communications and increase the message dissemination channels. Risk and health communication theories and techniques can be utilized to enhance message clarity and impact (DiClemente and Jackson 2016). For instance, the use of dynamic visual depictions may enhance effective communication and facilitate accurate information transfer. The visual depiction of "flattening the curve" has been used to convey social distancing recommendations based on complex epidemiological modeling (Anderson et al. 2020). A dynamic depiction of the virus' spread could show the increasing prevalence of COVID-19 across the USA over time. Diverse communication channels, strategies, and techniques are needed to facilitate message reach. News media outlets, predominantly those on television, are a major source of COVID-19 information. Other media, such as social media, blogs, and text messaging, can complement accurate news and may be harnessed to disseminate important information.

\section{Strengths and limitations}

Strengths of this study included a large sample size, the wide geographic distribution of participants, the use of theory-driven, validated scales and items, and the fact that data were collected during the peak of the pandemic, thus providing a snapshot of the perceptions and behaviors of the US population during a critical period of the crisis. However, the findings should be considered in the context of several limitations. First, given that the survey was opt-in, there is probably a bias towards respondents with greater interest in the subject. These respondents may differ in unmeasured, systematic ways from those uninterested in COVID-19. Second, the population from which the sample was drawn included only Facebook users. Although almost $70 \%$ of Americans use Facebook (of whom $74 \%$ use it daily), certain demographic groups, such as men and racial/ethnic minorities, are under-represented (Pew Research Center 2019). The demographic distribution of our respondents mirrors this disparity, with an over-representation of Non-Hispanic Whites and females. Consequently, this survey many not be generalizable to the US population and may not adequately reflect the perceptions and behaviors of other groups.

\section{Conclusions}

As the toll from COVID-19 continues to rise, there is a need to address both the community transmission and the concomitant mental health and substance-use consequences of the crisis. This requires a well-articulated, coordinated, and systematic pandemic control strategy; one based on science and effective behavior change and risk communication strategies. This study contributes to the vital evidence base needed to inform targeted public health interventions on disparities in knowledge, beliefs, and behaviors (including substance use) occurring during the COVID-19 pandemic. To increase the uptake and sustained practice of COVID-19 preventive behaviors requires utilizing theory- and empirically-based strategies with demonstrable evidence of effectiveness in meeting other health threats. Ultimately, reducing the transmission of COVID-19 will require an all-out effort (the public health equivalent of a 'full-court press' in basketball), with prevention messages aimed at addressing knowledge gaps, misconceptions, and practices, using the most effective social and behavioral science communications strategies.

Abbreviations ANOVA, Analysis of variance; $A O R$, Adjusted odds ratio; $C I$, Confidence interval; COVID-19, Novel coronavirus disease; 
$H B M$, Health Belief Model; IES, Impact of Event Scales; IQR, Interquartile range; $M E R S$, Middle East Respiratory Syndrome; $O R$, Odds ratio; $P H Q-4$, Patient Health Questionnaire; SARS, Severe Acute Respiratory Syndrome; $S D$, Standard deviation; WHO, World Health Organization

Supplementary Information The online version contains supplementary material available at https://doi.org/10.1007/s10389-021-01564-4.

Authors' contributions All authors have read and approved the manuscript. RJD: conceptualization, methodology, writing - review \& editing, supervision; AC: conceptualization, data curation, formal analysis, methodology, writing, original draft; SHA, AMJ, JF, YZ: data curation, methodology, writing — review \& editing.

Availability of data and materials The survey questionnaire can be found in the supplementary materials. The datasets used and analyzed during the current study, as well as the codebook, are available on ICSPR's COVID19 repository.

\section{Declarations}

Ethics approval and consent to participate The New York University Institutional Review Board reviewed and exempted the study procedures, ruling that no formal ethics approval was required to conduct this survey; the exception included consent to participate. Consent was assumed if the participants navigated to the site and completed the survey.

Competing interests The authors declare that they have no competing interests. Funding: no funding was receiving for conducting this study.

\section{References}

Abramson D (2020) Resilience in a pandemic of isolation. School of Global Public Health at New York University, NY. Retrieved April 25 from https://publichealth.nyu.edu/events-news/news/ 2020/04/24/resilience-pandemic-isolation

Ali SH, Foreman J, Capasso A, Jones A, Tozan Y, DiClemente RJ (2020) Social media as a recruitment platform for a nationwide online survey of COVID-19 knowledge, beliefs, and practices in the United States: methodology and feasibility analysis. BMC Med Res Methodol 20:116. https://doi.org/10.1186/s12874-020-01011-0

Al-Rabiaah A, Temsah MH, Al-Eyadhy AA, Hasan GM, Al-Zamil F, AlSubaie S, Alsohime F, Jamal A, Alhaboob A, Al-Saadi B, Somily AM (2020) Middle East respiratory syndrome-Corona virus (MERS-CoV) associated stress among medical students at a university teaching hospital in Saudi Arabia. J Infect Public Health 13(5). https://doi.org/10.1016/j.jiph.2020.01.005

Anderson RM, Heesterbeek H, Klinkenberg D, Hollingsworth TD (2020) How will country-based mitigation measures influence the course of the COVID-19 epidemic? Lancet 395(10228):931-934. https://doi. org/10.1016/S0140-6736(20)30567-5

Arons MM, Hatfield KM, Reddy SC, Kimball A, James A, Jacobs JR, Taylor J, Spicer K, Bardossy AC, Oakley LP, Tanwar S, Dyal JW, Harney J, Chisty Z, Bell JM, Methner M, Paul P, Carlson CM, McLaughlin HP, Thornburg N, Tong S, Tamin A, Tao Y, Uehara A, Harcourt J, Clark S, Brostrom-Smith C, Page LC, Kay M, Lewis J, Montgomery P, Stone ND, Clark TA, Honein MA, Duchin JS, Jernigan JA (2020) Presymptomatic SARS-CoV-2 infections and transmission in a skilled nursing facility. N Engl J Med 382:20812090. https://doi.org/10.1056/NEJMoa2008457
Bai Y, Yao L, Wei T, Tian F, Jin DY, Chen L, Wang M (2020) Presumed asymptomatic carrier transmission of COVID-19. JAMA 323(14): 1406-1407. https://doi.org/10.1001/jama.2020.2565

Bakker D, Kazantzis N, Rickwood D, Rickard N (2016) Mental health smartphone apps: review and evidence-based recommendations for future developments. JMIR Ment Health 3(1):e7. https://doi.org/10. 2196/mental.4984

Bakker D, Kazantzis N, Rickwood D, Rickard N (2018) A randomized controlled trial of three smartphone apps for enhancing public mental health. Behav Res Ther 109:75-83. https://doi.org/10.1016/j. brat.2018.08.003

Brooks SK, Webster RK, Smith LE, Woodland L, Wessely S, Greenberg N, Rubin GJ (2020) The psychological impact of quarantine and how to reduce it: rapid review of the evidence. Lancet 395(10227):912-920. https://doi.org/10.1016/s0140-6736(20) 30460-8

Brug J, Aro AR, Richardus JH (2009) Risk perceptions and behaviour: towards pandemic control of emerging infectious diseases : international research on risk perception in the control of emerging infectious diseases. Int J Behav Med 16(1):3-6. https://www.ncbi.nlm. nih.gov/pmc/articles/PMC7090788/pdf/12529_2008_Article_ 9000.pdf

Chan JF, Yuan S, Kok KH, To KK, Chu H, Yang J, Xing F, Liu J, Yip CC, Poon RW, Tsoi HW, Lo SK, Chan KH, Poon VK, Chan WM, Ip JD, Cai JP, Cheng VC, Chen H, Hui CK, Yuen KY (2020) A familial cluster of pneumonia associated with the 2019 novel coronavirus indicating person-to-person transmission: a study of a family cluster. Lancet 395(10223):514-523. https://doi.org/10.1016/ S0140-6736(20)30154-9

Chang SS, Stuckler D, Yip P, Gunnell D (2013) Impact of 2008 global economic crisis on suicide: time trend study in 54 countries. BMJ 347:f5239. https://doi.org/10.1136/bmj.f5239

Chen R, Chou K-R, Huang Y-J, Wang T-S, Liu S-Y, Ho L-Y (2006) Effects of a SARS prevention programme in Taiwan on nursing staff's anxiety, depression and sleep quality: a longitudinal survey. Int J Nurs Stud 43(2):215-225. https://doi.org/10.1016/j.ijnurstu. 2005.03.006

DiClemente R, Jackson JM (2016) Risk communication. In: International Encyclopedia of Public Health (pp. 378-382). Elsevier Inc., Amsterdam, The Netherlands

Dong E, Du H, Gardner L (2020) An interactive web-based dashboard to track COVID-19 in real time. Lancet Infect Dis 20(5):533-534. https://doi.org/10.1016/S1473-3099(20)30120-1

Durham DP, Casman EA (2012) Incorporating individual healthprotective decisions into disease transmission models: a mathematical framework. J R Soc Interface 9(68):562-570. https://doi.org/10. 1098/rsif.2011.0325

Elizarrarás-Rivas J, Vargas-Mendoza JE, Mayoral-García M, Matadamas-Zarate C, Elizarrarás-Cruz A, Taylor M, Agho K (2010) Psychological response of family members of patients hospitalised for influenza a/H1N1 in Oaxaca, Mexico. BMC Psychiatry 10(1):104. https://doi.org/10.1186/1471-244X-10-104

Fauci AS, Lane HC, Redfield RR (2020) Covid-19 - navigating the uncharted. N Engl J Med 382(13):1268-1269. https://doi.org/10.1056/ NEJMe2002387

Ferguson NM, Laydon D, Nedjati-Gilani G, Imai N, Ainslie K, Baguelin M, Bhatia S, Boonyasiri A, Cucunubá Z, Cuomo-Dannenburg G, Dighe A, Dorigatti I, Fu H, Gaythorpe K, Green W, Hamlet A, \& Hinsley W (2020) Impact of non-pharmaceutical interventions (NPIs) to reduce COVID-19 mortality and healthcare demand. Imperial College COVID-19 Response Team, London. https:// www.imperial.ac.uk/media/imperial-college/medicine/mrc-gida/ 2020-03-16-COVID19-Report-9.pdf

Friedrich MJ (2017) Depression is the leading cause of disability around the world. JAMA 317(15):1517. https://doi.org/10.1001/jama.2017. 3826 
Gandhi M, Yokoe DS, Havlir DV (2020) Asymptomatic transmission, the Achilles' heel of current strategies to control Covid-19. N Engl J Med 382:2158-2160. https://doi.org/10.1056/NEJMe2009758

Hartley DM, Perencevich EN (2020) Public health interventions for COVID-19: emerging evidence and implications for an evolving public health crisis. JAMA 323(19):1908-1909. https://doi.org/10. 1001/jama.2020.5910

Hasan F, Khan MO, Ali M (2018) Swine flu: knowledge, attitude, and practices survey of medical and dental students of Karachi. Cureus 10(1):e2048. https://doi.org/10.7759/cureus.2048

Horesh D, Brown AD (2020) Traumatic stress in the age of COVID-19: a call to close critical gaps and adapt to new realities. Psychol Trauma 12(4):331-335. https://doi.org/10.1037/tra0000592

IHME (2020) COVID-19 Projections: Social distancing assumed until infections minimized and containment implemented. IHME, Seattle, WA, USA. Retrieved April 28 from https://covid19. healthdata.org/united-states-of-america

Jalloh MF, Li W, Bunnell RE, Ethier KA, O’Leary A, Hageman KM, Sengeh P, Jalloh MB, Morgan O, Hersey S, Marston BJ, Dafae F, Redd JT (2018) Impact of Ebola experiences and risk perceptions on mental health in Sierra Leone, July 2015. BMJ Glob Health 3(2): e000471. https://doi.org/10.1136/bmjgh-2017-000471

Jaycox LH, Cohen JA, Mannarino AP, Walker DW, Langley AK, Gegenheimer KL, Scott M, Schonlau M (2010) Children's mental health care following hurricane Katrina: a field trial of traumafocused psychotherapies. J Trauma Stress 23(2):223-231. https:// doi.org/10.1002/jts. 20518

Keshtkar-Jahromi M, Sulkowski M, Holakouie-Naieni K (2020) Public masking: an urgent need to revise global policies to protect against novel coronavirus disease (COVID-19). Am J Trop Med Hyg 102(6):1160-1161. https://doi.org/10.4269/ajtmh.20-0305

Lau JTF, Yang X, Tsui H, Kim JH (2003) Monitoring community responses to the SARS epidemic in Hong Kong: from day 10 to day 62. J Epidemiol Community Health 57(11):864-870. https://doi. org/10.1136/jech.57.11.864

Lau JT, Yang X, Pang E, Tsui HY, Wong E, Wing YK (2005) SARSrelated perceptions in Hong Kong. Emerg Infect Dis 11(3):417-424. https://doi.org/10.3201/eid1 103.040675

Lau JT, Kim JH, Tsui H, Griffiths S (2007) Perceptions related to human avian influenza and their associations with anticipated psychological and behavioral responses at the onset of outbreak in the Hong Kong Chinese general population. Am J Infect Control 35(1):38-49. https://doi.org/10.1016/j.ajic.2006.07.010

Lau JTF, Griffiths S, DWH A, Choi KC (2011) Changes in knowledge, perceptions, preventive behaviours and psychological responses in the pre-community outbreak phase of the H1N1 epidemic. Epidemiol Infect 139(1):80-90. https://doi.org/10.1017/ S0950268810001925

Leung GM, Ho L-M, Chan SKK, Ho S-Y, Bacon-Shone J, Choy RYL, Hedley AJ, Lam T-H, Fielding R (2005) Longitudinal assessment of community psychobehavioral responses during and after the 2003 outbreak of severe acute respiratory syndrome in Hong Kong. Clin Infect Dis 40(12):1713-1720. https://doi.org/10.1086/429923

Lowe B, Wahl I, Rose M, Spitzer C, Glaesmer H, Wingenfeld K, Schneider A, Brahler E (2010) A 4-item measure of depression and anxiety: validation and standardization of the patient health Questionnaire-4 (PHQ-4) in the general population. J Affect Disord 122(1-2):86-95. https://doi.org/10.1016/j.jad.2009.06.019

Lu D, Bouey J (2020) Public mental health crisis during COVID-19 pandemic, China. Emerg Infect Dis J 26(7):1616-1618. https://doi. org/10.3201/eid2607.200407

Mak IWC, Chu CM, Pan PC, Yiu MGC, Chan VL (2009) Long-term psychiatric morbidities among SARS survivors. Gen Hosp Psychiatry 31(4):318-326. https://doi.org/10.1016/j.genhosppsych. 2009.03.001
Najimi A, Golshiri P (2013) Knowledge, beliefs and preventive behaviors regarding influenza a in students: a test of the health belief model. J Educ Health Promot 2:23-23. https://doi.org/10.4103/2277-9531. 112699

Painter JE, DiClemente RJ, von Fricken ME (2017) Interest in an Ebola vaccine among a U.S. national sample during the height of the 2014-2016 Ebola outbreak in West Africa. Vaccine 35(4):508512. https://doi.org/10.1016/j.vaccine.2016.11.093

Painter JE, von Fricken ME, de Viana OMS, DiClemente RJ (2018) Willingness to pay for an Ebola vaccine during the 2014-2016 Ebola outbreak in West Africa: results from a U.S. national sample. Hum Vaccin Immunother 14(7):1665-1671. https://doi.org/10. 1080/21645515.2018.1423928

Perrin A, Anderson M (2019) Share of U.S. adults using social media, including Facebook, is mostly unchanged since 2018. Pew Research Center, Washinton, DC, USA. Retrieved March 29 from https:// www.pewresearch.org/fact-tank/2019/04/10/share-of-u-s-adultsusing-social-media-including-facebook-is-mostly-unchangedsince-2018/

Person B, Sy F, Holton K, Govert B, Liang A (2004) Fear and stigma: the epidemic within the SARS outbreak. Emerg Infect Dis 10(2):358 363 https://www.ncbi.nlm.nih.gov/pmc/articles/PMC3322940/pdf/ 03-0750.pdf

Pew Research Center (2019) 10 facts about Americans and Facebook. Pew Research Center, Washington, DC, USA. Retrieved April 25 2020 from https://www.pewresearch.org/fact-tank/2019/05/16/ facts-about-americans-and-facebook/

Rothe C, Schunk M, Sothmann P, Bretzel G, Froeschl G, Wallrauch C, Zimmer T, Thiel V, Janke C, Guggemos W, Seilmaier M, Drosten C, Vollmar P, Zwirglmaier K, Zange S, Wolfel R, Hoelscher M (2020) Transmission of 2019-nCoV infection from an asymptomatic contact in Germany. N Engl J Med 382(10):970-971. https://doi. org/10.1056/NEJMc2001468

Rubin GJ, Amlot R, Page L, Wessely S (2009) Public perceptions, anxiety, and behaviour change in relation to the swine flu outbreak: cross-sectional telephone survey. BMJ 339:b2651. https://doi.org/ 10.1136/bmj.b2651

Shultz JM, Baingana F, Neria Y (2015) The 2014 Ebola outbreak and mental health: current status and recommended response. JAMA 313(6):567-568. https://doi.org/10.1001/jama.2014.17934

Shultz JM, Cooper JL, Baingana F, Oquendo MA, Espinel Z, Althouse BM, Marcelin LH, Towers S, Espinola M, McCoy CB, Mazurik L, Wainberg ML, Neria Y, Rechkemmer A (2016) The role of fearrelated behaviors in the 2013-2016 West Africa Ebola virus disease outbreak. Curr Psychiatry Rep 18(11):104 https://www.ncbi.nlm. nih.gov/pmc/articles/PMC5241909/pdf/11920_2016_Article_741. pdf

Smith A, Anderson M (2018) Social Media Use in 2018. Pew Research Center, Washington, DC, USA. Retrieved march 29 from https:// www.pewresearch.org/internet/2018/03/01/social-media-use-in2018/

AAPOR (2016) Standard definitions: final dispositions of case codes and outcome rates for surveys. American Association for Public Opinion Research, Washington, DC, USA. https://www.aapor.org/AAPOR Main/media/publications/Standard-Definitions20169theditionfinal. pdf

Thoresen S, Tambs K, Hussain A, Heir T, Johansen VA, Bisson JI (2010) Brief measure of posttraumatic stress reactions: impact of event Scale-6. Soc Psychiatry Psychiatr Epidemiol 45(3):405-412. https://doi.org/10.1007/s00127-009-0073-x

U.S. Census Bureau (1984) Census Regions and Divisions of the United States. U.S. Census Bureau, Washington, DC, USA. Retrieved April 23 from https://www2.census.gov/geo/pdfs/maps-data/maps/ reference/us_regdiv.pdf

Vartti AM, Oenema A, Schreck M, Uutela A, de Zwart O, Brug J, Aro AR (2009) SARS knowledge, perceptions, and behaviors: a 
comparison between Finns and the Dutch during the SARS outbreak in 2003. Int J Behav Med 16(1):41-48. https://doi.org/10.1007/ s12529-008-9004-6

Verity R, Okell LC, Dorigatti I, Winskill P, Whittaker C, Imai N, CuomoDannenburg G, Thompson H, Walker PGT, Fu H, Dighe A, Griffin JT, Baguelin M, Bhatia S, Boonyasiri A, Cori A, Cucunuba Z, FitzJohn R, Gaythorpe K, Green W, Hamlet A, Hinsley W, Laydon D, Nedjati-Gilani G, Riley S, van Elsland S, Volz E, Wang H, Wang Y, Xi X, Donnelly CA, Ghani AC, Ferguson NM (2020) Estimates of the severity of coronavirus disease 2019: a model-based analysis. Lancet Infect Dis 20(6):669-677. https:// doi.org/10.1016/S1473-3099(20)30243-7

Waelde LC, Uddo M, Marquett R, Ropelato M, Freightman S, Pardo A, Salazar J (2008) A pilot study of meditation for mental health workers following hurricane Katrina. J Trauma Stress 21(5):497500. https://doi.org/10.1002/jts.20365

Weiss D, Marmar C (1997) The impact of event scale. In: Wilson J, Keane T (eds) Assessing psychological trauma and PTSD. Guilford Press, New York

Wheaton MG, Abramowitz JS, Berman NC, Fabricant LE, Olatunji BO (2012) Psychological predictors of anxiety in response to the H1N1 (swine flu) pandemic. Cogn Ther Res 36(3):210-218. https://doi. org/10.1007/s10608-011-9353-3

Whitaker C, Stevelink S, Fear N (2017) The use of Facebook in recruiting participants for Health Research purposes: a systematic review. J Med Internet Res 19(8):e290

Wilson N, Kvalsvig A, Barnard LT, Baker MG (2020) Case-fatality risk estimates for COVID-19 calculated by using a lag time for fatality.
Emerg Infect Dis 26(6):1339-1441. https://doi.org/10.3201/ eid2606.200320

Wong TW, Gao Y, Tam WWS (2007a) Anxiety among university students during the SARS epidemic in Hong Kong. Stress Health 23(1):31-35. https://doi.org/10.1002/smi.1116

Wong W, Chan K, Tang H, Lam M (2007b) The cycle fear: a qualitative study of SARS and its impacts on kindergarten parents one year after the outbreak. Hong Kong Pract 29(4):146

World Health Organization (2020a) Coronavirus disease (COVID-19) outbreak situation. World Health Organisation, Geneva. Retrieved April 9 from https://www.who.int/emergencies/diseases/novelcoronavirus-2019

World Health Organization (2020b) Survey tool and guidance: rapid, simple, flexible behavioural insights on COVID-19. World Health Organisation, Geneva. http://www.euro.who.int/en/health-topics/ health-emergencies/coronavirus-covid-19/novel-coronavirus-2019ncov-technical-guidance/who-tool-for-behavioural-insights-oncovid-19

Wu P, Liu X, Fang Y, Fan B, Fuller CJ, Guan Z, Yao Z, Kong J, Lu J, Litvak IJ (2008) Alcohol abuse/dependence symptoms among hospital employees exposed to a SARS outbreak. Alcohol Alcohol 43(6):706-712. https://doi.org/10.1093/alcalc/agn073

Publisher's note Springer Nature remains neutral with regard to jurisdictional claims in published maps and institutional affiliations. 